\title{
Metáfora e Transferência
}

\author{
Metaphor and Transference
}

Valeska Zanello*

Instituto de Educação Superior de Brasília, Brasília, Brasil

\begin{abstract}
Resumo
O presente artigo tem como fito apontar em que sentido a transferência, no processo analítico, pode ser compreendida como metáfora. Utilizando o esquema gráfico construído por Searle (1995) para explicitar o processo que ocorre nas metáforas mortas, construímos uma analogia para compreender a transferência como uma metáfora morta (ainda que viva, no sentido de Lakoff e Johnson), que pode ser trazida para o plano da fala no campo analítico, ali onde o analista deve manter-se na ressonância de sua neutralidade e o analisando entre a repetição e seu trabalho de perlaboração. Ao final, é apresentado um excerto de um caso clínico para ilustrar o tema abordado.

Palavras-chave: Metáfora; transferência; Psicanálise.
\end{abstract}

\begin{abstract}
This article aims to point out the way that transference, in the psychoanalytical process, can be understood as a metaphor. We developed a graphic, in analogy of Searle's one, to understand transference as a dead metaphor (though yet alive, in the sense of Lakoff and Johnson) which can be brought to the dimension of speech in the analytical setting, where the analyst should maintain oneself in resonance with one's neutrality and the patient between repetition and working through work. To finalize, an excerpt of a clinical case is presented to illustrate the topics that are discussed.

Keywords: Metaphor, transference, psychoanalysis.
\end{abstract}

A primeira definição da palavra "metáfora” data da Grécia Antiga, nos escritos aristotélicos (Aristóteles, trad. 1999). Para Aristóteles, "metáfora é a transferência do nome de uma coisa para outra, ou do gênero para a espécie, ou da espécie para o gênero, ou de uma espécie para outra, ou por analogia” (p. 63, parágrafo 128). Ainda que a metáfora represente um mal a ser evitado no campo da argumentação filosófica, pois é geradora de equívocos, ela encontra um lugar específico no projeto aristotélico, qual seja, na Retórica e na Poética.

O conceito aristotélico de substituição presente na compreensão da metáfora vigorou por longo tempo na história do pensamento ocidental e nele podemos encontrar dois aspectos essenciais:

1. A troca da palavra própria pela imprópria (que passou cada vez mais a ser compreendida como forma de ornamentar o discurso).

2. A repetição freqüente desta troca, o que levou muitos autores pós-aristotélicos a distinguir uma metáfora "nova” de outra já desgastada pelo uso (metáfora "morta” ou literalizada). Segundo esta perspectiva, as metáforas "mortas" seriam facilmente parafraseáveis, sendo seu sentido praticamente literal, ao contrário das metáforas "vivas" (novas, criativas).

\footnotetext{
* Endereço para correspondência: SQN 310, Bloco M, Apt. 405, Brasília, DF, 70756130. E-mail: valeskazanello@uol.com.br

O presente artigo é parte da tese de doutoramento da autora (2005). Este trabalho contou com o apoio do CNPq.
}

Assistimos no final do século XIX e começo do século $\mathrm{XX}$ a uma renovação do interesse suscitado pela metáfora. Grande parte deste interesse levou à reformulação da compreensão da mesma, sobretudo no que tange ao aspecto "a" anteriormente citado, isto é, à reflexão dos mecanismos implicados na elaboração de uma metáfora. Testemunhamos, neste sentido, um "alargamento" do enfoque de compreensão do processo metafórico da palavra ao próprio ato de enunciação. Podemos resumir no seguinte esquema esta "reformulação":

1. Inicialmente a ênfase de compreensão da metáfora estava na palavra: a metáfora seria uma troca de uma palavra própria por outra imprópria. Este foi o caminho trilhado por Fontanier (1968), seguindo os passos aristotélicos.

2. Ênfase na proposição: A metáfora seria uma predicação inusual, como defende Black (1968) e Richards (1965). Há aqui uma extensão da palavra à frase, à proposição. A metáfora passa a ser vista como fruto da relação entre o sujeito (foco) e o predicado (quadro). É o caso do exemplo "Maria é uma flor", no qual passamos a ver Maria através do quadro "flor". Richards (1965) cita, curiosamente, o exemplo da própria transferência no processo analítico:

Os psicanalistas demonstram-nos com sua discussão da 'transferência' - outro nome para metáfora - o quanto constantemente modos de olhar, amar, agir, que se desenvolveram com um conjunto de coisas ou pessoas, são transferência de outro. Eles nos mostram principalmente a patologia 
destas transferências, casos nos quais o veículo - a atitude emprestada, a fixação parental -, tiraniza a nova situação, o teor, e o comportamento é inapropriado. A vítima está inapta para ver a nova pessoa exceto em termos da antiga paixão e seus acidentes. . . Mas num crescimento saudável, teor e veículo - a nova relação humana e a constelação familiar - co-operam livremente. (p. 135-136).

3. Ênfase no ato de enunciação (versus enunciado): Segundo esta perspectiva, o sentido metafórico não está no enunciado (em si), mas na discrepância entre aquilo que o falante intenciona dizer e aquilo que ele diz. Este foi o caminho trilhado por Grice (1982) e Searle (1995). Este último traçou os passos que seguimos quando realizamos a compreensão de uma metáfora (implicatura), por exemplo: (a) devemos acreditar que o falante não é louco e (b) devemos acreditar que aquilo que o falante diz tem algum sentido que ele, falante, espera e acredita que nós, como ouvintes, sejamos capazes de compreender.

4. Ênfase na escutação ${ }^{1}$ da metáfora e na redescrição de mundo que esta promove. Esta é a perspectiva de Paul Ricoeur (2000b): O autor vai aqui além da enunciação, pensando a linguagem não mais apenas como instrumento de ação (atos de fala), mas, seguindo os passos de Heidegger $(1981,1987)$, como constitutiva mesmo do mundo do "sujeito" (Zanello, 2004). Assim, por exemplo, uma paciente ao referir-se a si mesma como uma "leitoa gorda", não está apenas falando sobre a sua gordura, mas de um modo de sentir-se e dispor-se em relação a si mesma.

Paul Ricoeur (2000a) faz uma interessante distinção, no que tange ao aspecto "a" supracitado, entre o processo que ocorre no decorrer da realização de uma metáfora e seu produto ou resultado. Para ele, a transferência da palavra é o resultado do processo, cabendo então a pergunta altamente importante acerca do processo como isto se realiza.

De um modo geral, todos os pensadores que aqui apresentamos, resumidamente, questionam a redução do processo metafórico à simples transposição de uma palavra própria por outra imprópria. No entanto, pouca atenção ou reflexão foi dedicada à classificação da metáfora com os termos "morta" e "viva", de acordo com seu uso e sua inserção no cabedal lingüístico de uma determinada sociedade (item “b”). Peguemos como exemplo, para aprofundarmos um pouco mais este aspecto, a teoria dos atos de fala de Searle (1995). Para o filósofo teríamos três tipos de metáforas: as abertas, as simples e as mortas. Abaixo apresentamos uma tabela para explicitar esta diferenciação:

Interessa-nos aqui, sobretudo, que a diferenciação entre metáfora "viva" (seja ela aberta ou simples) e metáfora morta subsiste ${ }^{2}$. Para facilitar a compreensão desta última, Searle (1995) constrói um desenho, que apresentamos a seguir com o intuito de retomá-lo mais adiante:

Tabela 1

Diferenciação entre os Tipos de Metáfora, segundo Searle (1995)

Emissões metafóricas abertas
- Novidade, criatividade. Ex: "você e
eu somos dois fios desemcapados que
às vezes se tocam e geram as mais lou-
cas reações".

Número extenso de paráfrases. Ex: nossa relação é explosiva"; "nossa relação é cheia de choques (outra metáfora)"; "não damos certo"; "nossa relação é intensa e eletrizante (outra metáfora)", etc.

Maior sensação de insatisfação com a tradução. Podemos ver que muitas vezes a própria paráfrase é, neste caso, ela mesma metafórica.

Emissões metafóricas simples
- O uso já é mais sistemático, em pro-
cesso de lexicalização. Ex: uma
vendedora diz de um possível cliente que
entra na loja na qual trabalha: "Ih! é o
maior caroço!!". Neste meio, tal palavra
denota aquela pessoa que faz mil per-
guntas ao vendedor e sai de mãos vazi-
as (não dá “caldo”!).

Paráfrase simples. Ex: "Ih! Este cliente é daquele tipo que pergunta, pergunta, mas não compra nada!"

\begin{abstract}
Metáforas Mortas
- São lexicalizadas: Searle nem as denomina como emissão metafórica, pois de fato os princípios para a compreensão da metáfora já não são mais necessários. Ex: "Estou enfezado!" quer dizer "estou chateado, com raiva”, etc. e não o sentido original "estou cheio de fezes".

Não há paráfrase; o significado metafórico original passou a ser o significado literal. Ex: "Estou com muita raiva!"

Nem se pensa na tradução, o sentido é compreendido quase de forma automática.
\end{abstract}

Menor insatisfação com a tradução. Isto é, há mais consenso na comunidade lingüística acerca do que o falante pretendeu dizer.
1 Para Ricoeur (2000a), o trabalho da metáfora está mais na torção que a escuta do ouvinte faz do que na intenção do falante. Daí termos cunhado o termo "escutação".
2 Temos, já na nomenclatura, a primeira distinção que salta aos olhos: emissão metafórica versus metáforas mortas. Isto implica que nas metáforas mortas o sentido do falante (de enunciação) passou a ser o significado literal do enunciado. 
Metáforas Mortas - O significado original da sentença sai de circuito e a sentença adquire um novo significado literal, idêntico ao antigo significado metafórico de emissão. Passa-se do diagrama das emissões metafóricas acima ao diagrama das emissões literais.

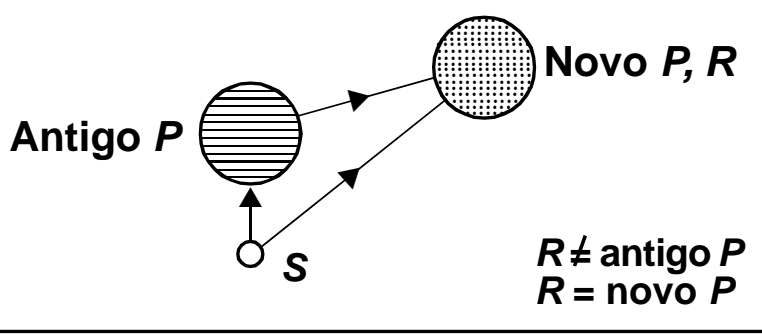

Figura 1. Esquema apontado por Searle (1995) para a compreensão das metáforas mortas.

Nesta figura, o autor propõe que o sentido, originariamente metafórico, se torna, pela repetição e pelo uso, o atual sentido literal da palavra ou da expressão. Isto é, o sujeito $\mathrm{S}$ chegava ao significado $\mathrm{R}$ passando pelo significado $\mathrm{P}$. Com a freqüência da repetição, o sujeito $S$ passa a chegar ao significado R diretamente. É o exemplo "estou enfezado!", presente em nosso quadro.

Sublinhamos que o aspecto "b" (diferença entre metáforas vivas e mortas), anteriormente citado, permaneceu intocado no decorrer de muito tempo e a despeito de várias críticas e das mais diversas contribuições teóricas. É com Lakoff e Johnson (1986) que tal aspecto será repensado.

Em seu livro Metáforas da vida cotidiana, os autores apontam não existir metáforas mortas! Segundo eles, as metáforas lexicalizadas pelo uso não são um fenômeno da língua, mas dizem respeito à estruturação da forma como percebemos o mundo e nele vivemos. Isto é, as metáforas mortas são as que estão mais vivas visto que, devido à sua repetição, elas acabam por estruturar nossa forma de ver, sentir, pensar, "ser no mundo". Como Richards (1965), mas em um outro sentido, os autores tomam aqui como exemplo o processo terapêutico (Lakoff \& Johnson, 1986):

Na terapia, por exemplo, grande parte da autocompreensão supõe reconhecer conscientemente metáforas previamente inconscientes e a maneira em que vivemos delas. Isto leva à construção constante de novas coerências na vida da pessoa, coerências que dão novo significado a experiências passadas. (p. 277-278).

Apesar de o uso da palavra "viva" ser específico e diferente de sua utilização anterior (abre o aspecto lingüístico para $o$ aspecto existencial), apontando assim para sentidos diferentes, acreditamos que este aporte cria um campo fértil para a realização de novas leituras do processo metafórico, bem como dos fenômenos de linguagem na clínica em sua imbricação com o modo de ser do sujeito. Em outras palavras, exploraremos esta diversidade de sentidos de "morta" e "viva" atribuídos à metáfora, como uma riqueza polifônica que nos instrumentará a pensar algo fundamental na impli- cação das pulsões de morte e das pulsões de vida, da repetição e da simbolização pela palavra, do mostrar e do dizer: a transferência. Neste sentido, o presente artigo tem como objetivo apontar o aspecto metafórico da transferência e seu lugar específico de imbricação entre o inominado e o vir-aser na palavra.

\section{Metáfora e Transferência}

Segundo Laplanche e Pontalis (1992), transferência “designa em psicanálise o processo pelo qual os desejos inconscientes se atualizam sobre determinados objetos no quadro de um certo tipo de relação estabelecida com eles e, eminentemente, no quadro da relação analítica" (p. 514). Isto é:

Trata-se aqui de uma repetição de protótipos infantis vivida com um sentimento de atualidade acentuada. . . . A transferência é classicamente reconhecida como o terreno em que se dá a problemática de um tratamento psicanalítico, pois são a sua instalação, as suas modalidades, a sua interpretação e a sua resolução que caracterizam este. (Laplanche \& Pontalis, 1992, p. 514).

Trata-se, segundo Freud (1912), de um método específico de conduzir-se na vida erótica, um clichê estereotípico constantemente repetido. $\mathrm{O}$ analista é assim colocado num determinado lugar pelo inconsciente do paciente: implica em repetição de um sentido que insiste em se realizar. Sendo o oposto (em um continuum) da recordação, Freud nos diz que a transferência é também a possibilidade preliminar para a nomeação e seu reconhecimento (Freud, 1920):

$\mathrm{O}$ paciente não pode recordar o que nele se acha recalcado, e o que não lhe é possível recordar, pode ser exatamente a parte essencial. Dessa maneira ele não adquire nenhum sentimento de convicção da correção da construção teórica que lhe foi comunicada. É obrigado a repetir o material recalcado como se fosse uma experiência contemporânea, em vez de, como o médico preferiria ver, recordá-lo como algo pertencente ao passado (p. 31).

Isto é, a transferência traz a possibilidade de o paciente experimentar seu vivido antes de ser nomeado: ela cria uma região intermediária entre a doença e a vida real (Freud, 1914).

A transferência cria, assim, uma região intermediária entre a doença e a vida real, através da qual a transição de uma para outra é efetuada. A nova condição assumiu todas as características da doença, mas representa uma doença artificial, que é, em todos os pontos, acessível à nossa intervenção. Trata-se de um fragmento de experiência real, mas um fragmento que foi tornado possível por condições especialmente favoráveis, e que é de natureza provisória. A partir das reações exibidas na transferência, somos levados ao longo dos caminhos familiares até o despertar das lembranças, que aparecem sem dificuldade, por assim di-

\footnotetext{
${ }^{3}$ Segundo o Langenscheidt (2001, p. 662), o termo pode ser traduzido por "aceitação; recebimento; recepção; aprovação; $\operatorname{ado}(\mathrm{p})$ ção; admissão . . .” Para Schneider (1993), o sentido do uso desse termo em Freud, trata-se da própria realização do afeto, sua aceitação e auto-implicação: adoção, assimilação, acolhimento em si.
} 
zer, após a resistência ter sido superada. (p. 201).

A vivência na e da transferência (e de sua repetição), fornece o sentimento de convicção ao paciente $\left(\right.$ Annahme $\left.{ }^{3}\right)$, elemento essencial para o sucesso terapêutico (Freud, 1920). Freud destaca, entre as possibilidades de transferência mais "perigosas", a erótica direta ou a agressiva em relação ao analista. São elas que impõem ao processo terapêutico as mais difíceis resistências. A maior tarefa da análise seria justamente removê-las ou elaborá-las (Freud, 1923, p. 2829), sendo também sua tarefa mais árdua, pois é no campo da transferência que a vitória deve ser conquistada. No entanto, encontramos no paciente a resistência contra a revelação das próprias resistências (Freud, 1937, p. 272). Além disto, a transferência cria e modifica a atmosfera de

$$
\text { Protótipo Analista }
$$

Figura 2. Esquema construído, em analogia ao de Searle (1995), para a compreensão da transferência.

base, Stimmung da análise, sendo fundamental o seu "manejo”. Podemos esquematizar, no desenho abaixo, construído em analogia ao de Searle (1995), a transferência:

Vemos, neste desenho, que o paciente vivencia com o analista uma situação, modo de portar-se (amar, odiar, competir, etc.) relacionado a protótipos infantis, sendo que o próprio protótipo encontra-se excluído da cena, sendo vivido como literalizado na pessoa do analista. É, neste sentido, que a transferência é uma metáfora, e morta (constantemente repetida...). Por outro lado, justamente por ser morta (caráter de literalização e sensação de "atualidade", recalque do protótipo infantil) é que ela é ainda mais viva (no sentido de Lakoff e Johnson), visto que estrutura o modo de ser e de portar-se do sujeito em relação ao outro. Trata-se aqui de repetir no lugar de rememorar (Freud, 1912), sendo portanto a resistência mais difícil, mas também das mais importantes para o processo analítico. A transferência mostra in vivo os conflitos do paciente. A ênfase deixa de ser agora o "ter o sintoma" para o "ser o sintoma”.

É a posição/atitude do analista, em sua neutralidade sua insistência no negativo- através do seu silêncio, da sua recusa de resposta ao inatual no atual (Fedida, 1978), em sua presença reservada, que criará o espaço potencial para que a transferência, enquanto metáfora "morta”, seja (re)metaforicizada, isto é, nomeada, trazida para o plano da nomeação, da palavra, da recordação. É neste sentido que a recomendação freudiana de neutralidade antes de ser ética, é técnica! (Figueiredo \& Coelho Junior, 2000)

Retomemos nosso desenho, construído como uma paráfrase gráfica sobre o de Searle (1995). Nele, podemos observar, como analogia, o espaço potencial mantido pelo analista na transferência. Se esta é vivida pelo paciente com o frescor da atualidade (literalizada) e de realidade, ligados aparentemente à pessoa do analista (o terceiro da transferência - o protótipo originário - não é percebido, ficando no pano de fundo, esquecido), a posição de neutralidade e o silêncio germinativo deste promovem a manutenção deste “terceiro" na cena: isto é, ele não adere ao que nele é colocado, apesar de não fugir deste espaço. Ele mantém sua escuta do inatual no atual, cultivando a não coincidência do terceiro ausente e sua própria pessoa (Fedida, 1991).

Para Fedida (1988), o trabalho analítico seria justamente significar, no momento adequado, a ausência do objeto ausente, podendo inclusive ter aí a metáfora falada ${ }^{4}$, na interpretação, um papel fundamental, sendo saída e passagem, configuração do vivido na linguagem ${ }^{5}$. O trabalho terapêutico deverá, assim, poder instaurar a possibilidade do diferente, onde o paciente só vê o semelhante: abertura de mobilidade e novas possibilidades. Trata-se também, segundo Figueiredo (1994), de uma abertura à temporalidade: ruptura e transição que se refere à passibilidade ao inesperado, ao surpreendente, ao impossível, pois como repetição, "o trauma não passa, não propicia o futuro e não constitui um presente: o trauma atemporaliza a existência” (p. 165). A “cura” seria a passagem do tempo sem tempo da "doença” para um tempo vivo, fluido e móvel. Neste sentido, podemos compreender a "doença” como a impossibilidade do fluir no vir-a-ser das metáforas de base, cristalização em determinadas metáforas eternamente repetidas (protótipos infantis), e desconsiderando de um modo geral, o contexto. É o que podemos ver no caso clínico a seguir.

Trata-se de Laura, paciente de 34 anos, em análise há seis meses. Há algo que sempre retorna em sua fala: situações nas quais se encontra disputando ou guerreando com outras pessoas. Mas vai ficando evidente que se trata sempre de outras mulheres... Digo a ela: "É curioso, você sempre entra em disputa com mulheres, mas com homens, raramente!”. Ela responde: “Nunca tinha pensado nisso!”. Fica um pouco quieta e recomeça: "Desde criança nunca gostei de brincar com as meninas, sempre preferi o grupo de meninos. Até hoje, se chego numa reunião, vou direto ficar no grupo ‘dos homens' (faz um gesto com a mão), porque acho chato demais o grupo das mulheres, os assuntos”. E continua suas associações. O interessante é que depois desta ses-

\footnotetext{
${ }^{4}$ Pretendemos abordar e aprofundar o tema do papel da nomeação exercido pela metáfora falada, tanto na associação livre quanto na interpretação, em um próximo artigo.

${ }^{5}$ Estamos nos referindo aqui somente ao trabalho com as psiconeuroses transferenciais. Como Imre Herman (1979) destaca, o problema das psiconeuroses narcísicas não é tanto a falta de lugar para a transferência, mas a dificuldade destes pacientes se desembaraçarem da idéia de realidade de suas transferências (p. 66). Segundo o autor, o psicótico não separaria facilmente a psicanálise da vida. Para Pirard (1980), é a metaforicização da estrutura que garantiria a possibilidade de metaforicização lingüística, isto é, a realização das implicaturas das metáforas faladas.
} 
são, na qual houve esta intervenção, a paciente começa a disputar comigo, a se mostrar inquieta, chegar atrasada, se 'esquecer' das sessões, dizer assim que entra no consultório: "Não estava com a menor vontade de vir!”, e a perguntar em sua fala no divã coisas como: "A psicologia é científica? Freud não era um louco?”. Não posso abrir a boca, que ela me pergunta diretamente: "Por que você disse isso? O que estava pressupondo?”. Seu tom é agressivo, irado, debochado. Enfim, a guerra agora é comigo, e na intensidade de sua transferência, as "bombas" são dirigidas a mim ou deslocadas para a própria situação analítica, ou à psicologia. Digo então a ela: “Tu tá querendo duelar comiiiiiiiiiiiiigooooo né? Tchau guerreira!”. Ela permanece qualquer instante deitada, seu rosto fica vermelho, ela ri muito, mas parece sentir também muita raiva. Se levanta, me olha e diz: “Tu é de lascar!!”. E ri, mais relaxada.

$\mathrm{Na}$ sessão seguinte retoma o que havia acontecido. Diz que sentiu muita raiva, mas depois se pegou rindo de si mesma, que se lembrou de uma coisa que precisa me contar. Passa então a contar lembranças da relação com sua mãe (de quem ela nunca falava, parecendo mesmo evitar o assunto), de quanto disputava com ela, que ela era guerreira desde criança.

Após aquela interpretação, o que vai emergindo é um amor e um rancor imenso da paciente, misturado pelos ciúmes da relação da mãe com os irmãos. Fica evidente que ela não sabia pedir nem dizer este amor. As sessões seguintes foram extremamente mobilizadoras e colocaram em evidência que "os fenômenos da transferência são obviamente explorados pela resistência que o Eu mantém em sua pertinaz insistência no recalque” (Freud, 1920). Ao se trabalhar a resistência, abre-se a via para a lembrança emergir na palavra. A paciente passa a brincar consigo mesma, quando se percebe em situações de conflito, ela me conta que diz a si mesma: "Ihhhhhh!! Lá vem a guerreira!” E pode rir, e pode não ser guerreira (tendo o humor aqui papel fundamental).

A passagem do vivido "metafórico" (a metáfora morta viva) para a fala, num processo de uso da metáfora (em sua função de nomeação), garante a vivacidade desta que adquire aqui na singularidade do psiquismo e da história do sujeito toda sua importância. Trata-se de uma primeira “objetivação" do sintoma, num processo genuíno de simbolização. O que se repete pede palavra. A metáfora morta que insiste em se fazer viva nesta repetição, pede para se tornar viva através de sua primeira morte efetuada pela circulação da palavra.

Parece-nos que a idéia de "morte" e "vida” não são apenas uma questão para a última tópica freudiana, sendo aqui, para nós também, limite e trampolim. Novamente tocamos, nesta interface, a difícil questão de imbricar morte e vida, de traduzir o mudo do que se mostra na repetição, na intensidade viva do dito. Trata-se, como nos diz Viderman (1990), de:

.. percorrer boas distâncias (percurso que, como já vimos, colocará à prova a inventividade do analista) para tentar juntar o desconhecível da pulsão e a representação que a diz, isto é, a linguagem que a estrutura, por meio da qual ela se dá um nome. . . . Se da pulsão nunca percebemos senão sombras na parede- é preciso fazer de tal modo que elas se projetem no campo transferencial e sejam bastante denunciadas ali para que um possa conhecê-la e o outro reconhecê-la como sua. (p. 275).

Trata-se, de um lado, do trabalho de (re)metaforicização do analista, através de sua escuta e de seu trabalho de interpretação, mantendo-se na persistência de sua neutralidade, e, por outro lado, do trabalho de perlaboração e (re)conhecimento do analisando. Campo proporcionado na e pela transferência.

\section{Referências}

Aristóteles (trad. 1999). Poética: Os Pensadores. São Paulo, SP: Abril.

Black, M. (1968). Models and metaphors: Studies in language and Philosophy. New York: Itaca.

Fedida, P. (1978). Le vide de la métaphore et le temps de l'intervalle. In P. Fedida (Ed.), L'Absence (pp. 197-238.). Paris: Gallimard.

Fedida, P. (1988). Amor e morte na transferência. In P. Fedida (Ed.), Clínica psicanalítica: Estudos (pp. 21-66). São Paulo, SP: Escuta.

Fedida, P. (1991). Do sonho à linguagem. In P. Fedida (Ed.), Nome, figura e memória: A linguagem na situação psicanalítica (pp. 1350). São Paulo, SP: Escuta.

Figueiredo, L. C. (1994). Fala e acontecimento em análise. In L. C. Figueiredo (Ed.), Escutar, recordar, dizer: Encontros heideggerianos com a clínica psicanalítica (pp. 149-169). São Paulo, SP: Escuta/EDUC.

Figueiredo, L. C., \& Coelho, N., Jr. (2000). Ética e técnica em Psicanálise. São Paulo, SP: Escuta.

Fontanier, P. (1968). Figures du discours. Paris: Flammarion.

Freud, S. (1912). A dinâmica da transferência. In Edição Standard Brasileira das Obras Completas de Sigmund Freud: Vol. 12 (pp. 131143). Rio de Janeiro, RJ: Imago.

Freud, S. (1914). Recordar, repetir e elaborar: Novas recomendações sobre a técnica da Psicanálise II. In Edição Standard Brasileira das Obras Completas de Sigmund Freud: Vol. 12 (pp. 193207). Rio de Janeiro, RJ: Imago.

Freud, S. (1920). Além do princípio do prazer. In Edição Standard Brasileira das Obras Completas de Sigmund Freud: Vol. 18 (pp. 1385). Rio de Janeiro, RJ: Imago.

Freud, S. (1923). O Ego e o Id. In Edição Standard Brasileira das Obras Completas de Sigmund Freud: Vol. 19 (pp. 23-90). Rio de Janeiro, RJ: Imago.

Freud, S. (1937). Análise terminável e interminável. In Edição Standard Brasileira das Obras Completas de Sigmund Freud: Vol. 23 (pp. 241-287). Rio de Janeiro, RJ: Imago.

Grice, P. (1982). Lógica e Conversação. In M. Dascal (Ed.), Fundamentos metodológicos de Lingüística (pp. 81-103). Campinas, SP: Editora da Universidade de Campinas.

Heidegger, M. (1981). A origem da obra de arte. Lisboa, Portugal: Edições 70.

Heidegger, M. (1987). De camino al habla. Barcelona, España: Odós.

Herman, I. (1979). La Psychanalyse comme méthode. Paris: Denoel.

Lakoff, G., \& Johnson, M. (1986). Metaforas de la vida cotidiana. Madrid, España: Catedra. 
Langenscheidt. (Ed.). (2001). Langenscheidt Taschenwörterbuch Portugiesisch. Berlim, Germany: Graph. Betriebe Langenscheidt.

Laplanche, J., \& Pontalis, J.-B. (1992). Vocabulário da Psicanálise. São Paulo, SP: Martins Fontes.

Pirard, R. (1980). Symbole, symptôme et métaphore: A la recherche d'une articulation. La Métaphore - approche pluridisciplinaire, 1, 141-184.

Richards, I. A. (1965). The Philosophy of Rhetoric. New York: Oxford University Press.

Ricoeur, P. (2000a). A metáfora viva. São Paulo, SP: Martins fontes.
Ricoeur, P. (2000b). Teoria da interpretação. Lisboa, Portugal: Edições 70.

Schneider, M. (1993). Afeto e linguagem nos primeiros escritos de Freud. São Paulo, SP: Escuta.

Searle, J. (1995). Expressão e significado: Estudo da teoria dos atos de fala. São Paulo, SP: Martins Fontes.

Viderman, S. (1990). A construção do espaço analítico. São Paulo, SP: Escuta.

Zanello, V. (2004). A linguagem poética em Heidegger. Educação e Filosofia, 18, 279-310.

Zanello, V. (2005). A metáfora no trabalho clínico: Ensaios teóricoclínicos acerca das funções da metáfora na clínica cotidiana. Tese de Doutorado não-publicada, Curso de Pós-Graduação em Psicologia Clínica, Universidade de Brasília, DF.

Recebido: $16 / 11 / 2005$ $1^{a}$ revisão: $21 / 03 / 2006$ Aceite final: 19/07/2006 